\title{
IMPACT OF ENVY ON INTERPERSONAL CONFLICT WITH MEDIATING ROLE OF SCHADENFREUDE AND MODERATING ROLE OF WORK ETHICS AMONG NURSES IN PAKISTAN
}

\author{
NIDA ABBAS \\ SANA FARZAND ALI \\ SYEDA FIZZA \\ Capital University of Science \& Technology, Islamabad, Pakistan
}

\begin{abstract}
The objective of this study was to examine the impact of envy on interpersonal conflict, through the mechanism of schadenfreude and the moderating effect of work ethics, among nurses in Pakistan. Convenient sampling technique was used in order to draw the sample. Data were collected from 200 employed nurses who had been working at different levels in Pakistani hospitals. Regression analysis was run in order to test the hypotheses. Study findings suggested that Envy is positively associated with interpersonal conflict, while schadenfreude partially mediates this relationship. In addition, work ethics moderates the association such that it weakens the positive relationship between schadenfreude and interpersonal conflict. The paper concludes by discussing the limitations as well as future research directions.
\end{abstract}

\section{INTRODUCTION}

Man cannot survive in this world in isolation. He is bound to live in a society and as a result develops interpersonal relationships. These relationships may have a huge positive impact on an individual's life (Berscheid \& Reis, 1998), but there is a darker side to these relationships. A study by Veroff, Douvan, \& Kulka, (1981) found that interpersonal conflicts are the most common cause of sadness among employees. In literature, interpersonal conflict has been defined in numerous ways. According to Barki, \& Hartwick, (2001), "it is a phenomenon that arises among symbiotic parties as a result of negative reactions to perceived disagreements and interference with the accomplishment of goals." Interpersonal conflict among individuals can arise as a result of adverse emotions.

Humans are a complex construct of nature, with manifold emotions. These emotions are one of the aspects that differentiate humans from animals, as humans experience multifaceted emotions (Panksepp, 1998; Darwin, 1998). Over the past era, a lot of research has been conducted across the world, on how employees exhibit their emotions at workplace (Rafaeli \& Sutton, 1989; Ashforth \& Humphrey, 1995; Wharton \& Erickson, 1993; Muchinsky, 2000); as these emotions, either positive or negative can affect the overall organization (Staw, Sutton \& Pelled, 1994).
Research suggests when an employee experiences positive emotions at workplace; he/she is least likely to undergo negative emotions at the same time (Fredrickson, 2003).

In today's competitive workplace, many employees are continuously facing challenges to prove their worth in their organizations. However, in order to prove themselves, they face numerous emotions, which more often than not are negative. One of such emotions, employees face is envy (Dogan, \& Vecchio, 2001). Generally the term envy is an emotion that emerges in an individual when he lacks the superior quality of another person (Parrott \& Smith, 1993). Envy results in the feeling of inferiority, rendering it unwelcomed in the workplace (Smith, Parrot, Ozer \& Moniz, 1994). At times, envy and jealousy are used interchangeably, although these are two different emotions (Bedeian, 1995). In jealousy, the fear of losing the other person is involved; however, this fear does not exist in envy. Literature suggests that malicious envy leads to schadenfreude (DeWall, et al., 2014).

Humans are designed in such a way, that they exhibit various emotions. At one point an individual may feel sympathetic when seeing his fellows suffer, but he may feel pleased as well, simultaneously. In literature, this devilish feeling of pleasure is labeled as schadenfreude (Takahashi et al., 2009). It develops as a result of perceived inferiority (Smith et al. 1996) and is destructive for the society (Heider, 1958). 
Schadenfreude is a facet of joy (Ekman, 2003). Furthermore, studies have shown that schadenfreude can result in conflict (Li, 2012; Takahashi et al., 2009; Cikara \& Fiske, 2013). The current study intends to investigate "How envy can lead to interpersonal conflict through schadenfreude and how work ethics would moderate this relationship? The focus of the study is to measure the extent to which envy and schadenfreude develop interpersonal conflict among nurses in Pakistan. And to what extend work ethics control these negative emotions in the workplace. The supporting theory for the study is Social Comparison Theory presented by social psychologist Leon Festinger (1954). The social comparison theory states that humans determine their social and personal worth based on how they stack up against others. Consequently, humans are continuously evaluating themselves with others on the basis of various attributes. At time this comparison can sow the seed of hatred among individuals.

The study intends to fill the contextual gap by empirically exploring the relationship of envy and interpersonal conflict, through schadenfreude. Not only the study aims to fill this contextual gap, it intends to provide some insight into medical profession and how nursing profession can benefit from such a research. Moreover, there is a lack of any substantiated research in Pakistan in the field of management (Aycan et.al, 2000) and other related fields. Nurses are believed to be the most affected by negative emotions as they have to interact with people both within and outside the organization, on daily basis, i.e. doctors and patients, respectively. All these aspects can lead to negative emotions and interpersonal conflict. In today's competitive world, the main focus of organizations is to be more productive as compared to the competitors. For better output, the behavior of employees in an organization plays an important part. Since their actions benefit or harm the organization.

\section{LITERATURE REVIEW}

\section{Envy and Interpersonal Conflict}

Humans are the most complex machine on the face of the earth; and what make them complex are emotions. Different emotions, feelings and cognitions are what trigger behaviors. Envy, is one of those emotions that leads to certain behavioral outcomes. Word envy has been defined in several contexts, going back as farther as the biblical times, as it is one of the seven deadly sins. Merriam Webster Dictionary defines envy as "Painful or resentful awareness of an advantage enjoyed by another, joined with a desire to possess the same advantage." Over a long period of time, many scholars have defined envy, including renowned philosophers and sociologists such as Freud, Nietzsche, Rawls, Nozick and Schoeck to name a few. Rawls (1971) described envy 'as the propensity to view with hostility the greater good of others even though their being more fortunate than we are does not detract from our advantages'.

Literature suggests that people have interdependent preferences (Cabrales, 2010), which cause individuals to make comparisons on certain basis. The comparison may not be merely income based, as it must have relevance, e.g. person A might not envy person B, on the basis of income differences if $\mathrm{B}$ is spending his/her money on things that are not important for A (Chaudhuri, 1985). Feather and Nairn (2005), concur to the concept of personal relevance, as they suggest that envy due to the social comparison must have selfrelevance for the person making comparison, i.e. only if it is in realm that holds importance for self (Heider, 1958). Only when the comparison domain is selfrelevant, would an individual experience envy when the target person's possession is superior and in the absence of self-relevance, individual does not feel envy even if the possession of the target person is far superior (Takahashi et al., 2009). Even though millionaires, celebrities and leaders hold envied positions, people are most likely to envy those with whom they directly vie in their day-to-day matters (Hill \& Buss, 2006).

The conflicts are said to exist whenever there are differences in the individual goals and outcomes (Jameson, 1999), as these differences occur due to difference in perception and psychic make up. Humans are social beings by nature. They grow up in families and social communities and are always a part of social and work organizations. Therefore, it is not surprising that human behaviors, affect and cognitions have a great influence on the interpersonal relationship (Frone, 2000). Interpersonal conflict is a cognitive conflict (Dhami and Olsson, 2008). The concept of Interpersonal Conflict is operationalized by many researchers, such as Barki and Hartwick (2004), who identified the three general properties associated with any conflict, i.e. Disagreement, Interference and Negative Emotion, along with the two types of targets of interpersonal conflict, i.e. task and interpersonal relation between parties. Interpersonal conflicts are often based on lack of communication, pride, emotionalism, lack of trust, hostility and frustration (Barki \& Hartwrick, 2001; Scott, 2007). When individuals are tied up in interpersonal relation, the experience of tension, anxiety and anger are obvious (Fitzpatrick and Winke, 2009). Negative emotions are the important elements of the composition of personality, therefore, personality type is also one strong predictor of determining the 
orientation of interpersonal conflict; although, it has a little impact than situational and relationship variables, it modes the individual reactions towards the conflict (Greenhalgh, Nelsin \& Gilkey, 1985).

Once negative emotions and feelings are involved in the relationships at work, most of the times it causes the conflict at interpersonal level. This conflict can be due to differences in interests and motives. This clearly indicates that interpersonal conflict has its direct impact on the task performed at work place. Interpersonal conflict is the matter of concern, because it poses the threat to well-being of employees by increasing work related problems and ultimately it harms the team and organizational performance (Leung, 2008).

But in some instances when interpersonal conflict is purely targeted at task, it would be effective for team performance in organization (Jehn, 1997). Conversely, interpersonal conflict can become one strong reason for job dissatisfaction. However, interpersonal conflict's adverse effects are less likely to affect job satisfaction in the presence of social support (Corts, Benitez, Boz, Munduate \& Medina, 2011).

Moreover, literature also suggests that envy is one of the factors that causes conflict in the workplace (Simmel, 2010). Because employees want to dominate their peers in the workplace and if they fail to do so, they develop a feeling of envy (Cabrales, 2010). Hence, to examine the link between envy and interpersonal conflict following hypothesis is developed:

\section{Hypothesis 1. Envy leads to interpersonal conflict}

\section{Schadenfreude as a mediator}

Envy takes several forms and leads to certain behavioral outcomes based on the intensity. Barth (2008) suggested that it should be seen as a scale ranging from benign to malignant and destructive. When a person experiences envy, he/she may use different strategies in order to reduce the envious emotions. A person might try to depart from the situation or group, try to change their own behavior or finally, he/she may try to harm the other person (Nickerson \& Zenger, 2008). It leads to certain behavioral outcomes; one of the most common outcomes is experiencing pleasure from the misfortune of the envied person, also known as Schadenfreude. An individual feeling envy often desires to possess the same advantage as the envied person or at times wishes the envied person a misfortune in order to reduce the envious emotions.

Numerous evidences of an established link between envy and Schadenfreude are present in literature (Hareli \& Weiner, 2002; Kim, O’Neill \& Cho, 2010). Envy leads to Schadenfreude, signifying that an individual feeling stronger envy would lead to the stronger Schadenfreude, i.e. deriving pleasure from the misfortune of the other people (Takahashi, Kato, Matsuura, Mobbs, Suhara \& Okubo, 2009). Sue Cowan-Jenssen (2011) in her paper Envy: Everyday and Everywhere implies that when an individual experiences envy he/she may even feel delighted if any bad luck or calamity occurs to the envied person. Likewise, Smith et al. (1996) established that Envy leads to Schadenfreude mediated by episodic envy. They proposed that a person feels happy when an envied person faces a set-back or suffers a misfortune. As envy at times causes anger and hostility, it may lead to the pleasure derived by the misfortune of the other person (Schadenfreude), mediated by these negative emotions such as anger, hostility, etc. (Hareli \& Weiner, 2002). Stronger envy leads to the stronger negative emotions towards the envied person (Kim, O'Neill \& Cho, 2010).

On the basis of aforementioned arguments and the words of Heraclitus: Our envy always lasts longer than the happiness of those we envy, the following hypothesis has been developed:

\section{Hypothesis 2. Envy is positively related to the Schadenfreude}

Every time we hear of a misfortunate occurrence to a person, we feel sympathetic towards them, but there are times, when an individual may feel pleased by any misfortune befalling another person. This feeling of pleasure derived by the misfortune of the other is known as Schadenfreude (Merriam Webster Dictionary). Nietzsche (1967) in his work on the genealogy of morals, differentiated between the pleasures derived from passively "seeing" someone suffer (Schadenfreude) and actively "making" others suffer. Although the definition of the term goes way back to the time of philosophers such as Nietzsche, Socrates and Plato, the empirical studies were only conducted from late 1990s and onwards. Several studies indicate the antecedents of Schadenfreude, varying from pleasure from misfortune due to envy (Smith et al., 1996; Van Dijik, et al., 2006), negative emotions such as anger and resentment (Hareli \& Weiner, 2002; Van Djik et al., 2006; Feather \& Sherman, 2002). Literature provides numerous evidences of an established link between envy and Schadenfreude. A large part of research considers envy as an antecedent of Schadenfreude (Takahashi, et al., 2009). Similarly, envy leads to Schadenfreude when hostile feelings of envy are incorporated as well as the likeness between the envied and the envying person (Van Dijik, et al., 2006). Apart from envy and negative emotions, 
perceived deservingness of the misfortune also plays a vital role in determining the causes of Schadenfreude (Van Dijk, Ouwerkerk, Goslinga \& Nieweg, 2005). If an individual feels that the person is deserving of the misfortune befalling him/her, it will result in higher Schadenfreude; on the contrary, if the perceived deservingness of the misfortune is lower, then a person would rather feel sympathetic towards a person in the face of the misfortune (Van Dijk, Ouwerkerk, Goslinga \& Nieweg, 2005). Additionally, Powell and Smith (2013) in their paper Schadenfreude Caused by the Exposure of Hypocrisy in Others established that people experience strong Schadenfreude when a person who is caught in the immoral action has himself/ herself criticized others for the similar actions, which indicates that perceived hypocrisy also leads to higher Schadenfreude.

Leach, Spears, Branscombe \& Doosje (2003) in their paper Malicious Pleasure: Schadenfreude at the Suffering of Another Group, have examined the nature of intergroup relationships and their impact on pleasure derived from the misfortune of the other group. They studied intergroup Schadenfreude on the basis of interest in domain, threat of an in-group inferiority and legitimacy. The results showed higher interest in the domain among group and higher threat to in-group inferiority will lead to higher Schadenfreude. On the other hand, if the other group is legitimately superior, this results in lower Schadenfreude when the in-group is urged to be honest and direct. They used Social identity theory and intergroup emotion perspective to operate intergroup Schadenfreude. The likeness or disliking of an out-group has been proven to affect interpersonal schadenfreude (Smith et al., 1996) and in response this might affect or give way to the negative emotions towards out-group whether or not they suffer misfortune (Leach, Spears, Branscombe \& Doosje, 2003). This could lead to one of the many inter-group outcomes, i.e. interpersonal conflict.

Therefore, on the basis of the above argument, following hypotheses have been developed:

Hypothesis 3. Schadenfreude is positively related to the interpersonal conflict

Hypothesis 4. Schadenfreude mediates the relationship between envy and interpersonal conflict

\section{Work Ethics as a moderator}

Ethics are the code of conduct for any activity, situation, or event. These are the moral standards that an individual possess and these standards vary according to situations (Scribner, 1993). Work ethics can be defined as a set of beliefs, values and attitudes that reflect the fundamentals of work and it is an integrated construct of attitudes and beliefs related to work behavior (Miller et al., 2002). Work ethics are basically the work values. These values or attitudes and beliefs actually form the human thinking and actions and enable individuals to distinguish between right and wrong.

Work values or work ethics have been treated as a moderator in many studies. Work Ethics have been measured as moderators of task dimensions and affective responses (Aldag \& Breif, 1975). Similarly, ethical climate moderated the relation of individual decision and behavior, which shows that ethics influence the individual's behavior, as behaviors are based on perceptions and situations; therefore, ethics can be related to conflicts at individual level (Barnett \& Vaicys, 2000). Individuals in organizations always judge other people by making the statements like "his/ her action or decisions are not right or wrong" (Virovere, Kooskora \& Valler, 2002). McCabe and Rabil (2002) argued that absence of fair treatment, ethical value, and practices can create or augment the causes of conflict in organizations. Ethics always prevent the individuals from conflicts of interest, misrepresentation of facts, lying, cover up and deceit or manipulation in the work place (Baker, 1994). Based on this, ethics could be believed to have impact on schadenfreude, as finding pleasure at someone else's misfortune can be considered anything but ethical. Therefore, the following hypothesis has been developed:

\section{Hypothesis 5. Work Ethics negatively moderate the relationship between schadenfreude and interpersonal conflict}

\section{THEORETICAL FRAMEWORK}

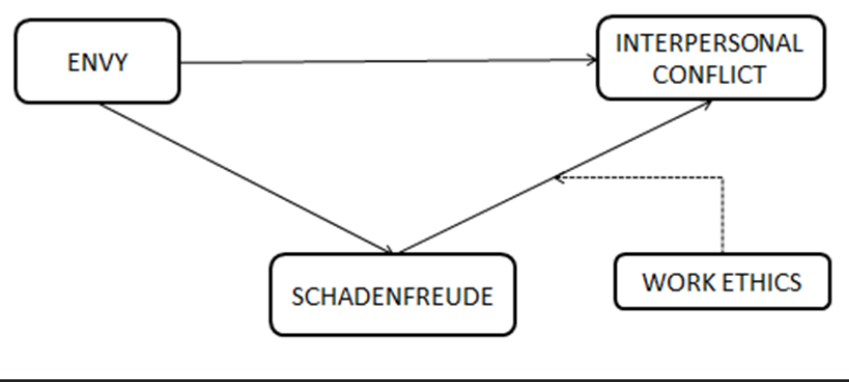

METHODOLOGY

\section{Sample and Procedure}

The present research is a cross sectional study 
of descriptive nature, as research has already been conducted in this area. Moreover, it is a casual type of investigating. The unit of analysis for the study is individual as data were gathered from the nurses working in private and public hospitals in the region of Rawalpindi and Islamabad. The population of the present study consists of nursing staff currently employed in Pakistan. Convenient sampling technique was used in order to draw the samples. Almost 300 questionnaires were distributed; out of which only $200(70.3 \%)$ questionnaires were filled completely and returned.

The sample consisted of $82 \%$ females and $17 \%$ male nurses. Out of which, $60 \%$ were between the ages of $15-25$ and $33 \%$ belonged to the age group 2635 ; whereas, only $3.5 \%$ respondents were over the age of 45 . Among the respondents $59 \%$ had $1-5$ years of work experience, $18 \%$ had less than one year of experience. However, $13.4 \%$ had 6-10 years of working experience and only $10 \%$ respondents had more than ten years of working experience. In the sample, $60.4 \%$ respondents held a bachelor degree, whereas, $39.6 \%$ of the respondents undergraduates.

\section{Instrumentation}

Data were collected using questionnaires, which have been adopted from the work of early researchers to evaluate the variables of the present study.

\section{Envy}

In order to measure envy, questionnaire developed by Vecchio (2005) was adopted. All the concepts together were evaluated using the likert scale, whereby score 1 (strongly disagree) to score 5 (strongly agree). The Cronbach's Alpha value for reliability of envy was 0.652 .

\section{Schadenfreude}

For schadenfreude a questionnaires having 08 items, developed by Van Dijk et al., (2006) and James et al., (2014) were used. The Cronbach's Alpha value for reliability of schadenfreude was 0.626 but after deleting item 24 from the questionnaire it was raised to 0.696 .

\section{Interpersonal Conflict}

Interpersonal conflict was measured using five item questionnaire, adopted from the work of Spector, \& Jex, (1998). The Cronbach's Alpha value for reliability of the scale was 0.617 . However, after removing item number 14 from the questionnaire it was raised to 0.693 .

\section{Work Ethics}

Work ethics was measured using five item questionnaire, developed by Miller, Woehr \& Hudspeth, (2002). The Cronbach's Alpha value for reliability of the scale was 0.818 .

\section{RESULTS}

Data were analyzed using Regression analysis, in order to test the hypotheses. Table (1) depicts mean, standard deviation, correlation and reliabilities of variables. The mean for envy and schadenfreude were 2.83 and 2.76 , respectively. The correlation between these two constructs was $.137^{*}$, indicating significant positive correlation between envy and schadenfreude.

Similarly, the correlation analysis further showed that envy is significantly and positive correlated with interpersonal conflict; whereas, interpersonal conflict was found to be negatively related to work ethics but with no significance.

\section{Regression Analysis}

Mediation and moderation analyses were run using Preacher and Hayes method (2008), in order to formally test the hypotheses. In all the regression tests age, gender, tenure, and education were entered as controlled variables in the first step. Mediation regression analysis was used to test the mediating role of schadenfreude between envy and interpersonal conflict.

TABLE 1

Means, standard deviation, correlation and reliabilities

\begin{tabular}{llcccccc}
\hline \multicolumn{1}{c}{ Variables } & Mean & SD & $\mathbf{1}$ & $\mathbf{2}$ & $\mathbf{3}$ & $\mathbf{4}$ \\
\hline 1 & Envy & 2.83 & 0.85 & $(.652)$ & & & \\
2 & Schadenfreude & 2.76 & 0.65 & $.137^{*}$ & $(.696)$ & & \\
3 & Interpersonal conflict & 3.25 & 0.92 & $.207^{* *}$ & $.215^{* *}$ & $(.693)$ & \\
4 & Work ethics & 4.28 & 0.58 & .050 & 0.16 & -.015 & $(.818)$ \\
\hline
\end{tabular}

$N=211$; alpha reliabilities are given in Parentheses. For correlation greater than or equal to $.316 p<.05^{*}$; for correlations greater than or equal to .183; $<<0.01 * *$ 
TABLE 2

Regression Mediation Analysis

\begin{tabular}{lcccc}
\hline & \multicolumn{2}{c}{ Interpersonal Conflict } & P \\
\hline Variables paths & Beta & SE & T & 2 \\
Path a: IV to M & 0.11 & 0.05 & 2.83 & 0.05 \\
Path b: M to DV & 0.27 & 0.10 & 3.060 & 0.01 \\
Path c: IV to DV & 0.225 & 0.074 & 2.694 & 0.003 \\
Path c': & 0.197 & 0.073 & 0.008 \\
\hline
\end{tabular}

All the demographic variables (age, gander, tenure, education, and hospital type) were controlled initially, $M$ (Mediating variable) is used i.e. schadenfreude, Path c'shows the total effect

TABLE 3

Regression Moderation Analysis

\begin{tabular}{ccccccc}
\hline Variables & Work ethics & \multicolumn{3}{c}{ Direct (Interpersonal Conflict) } \\
& $\mathbf{R}^{\mathbf{2}}$ & $\mathbf{F}$ & $\mathbf{P}$ & $\mathbf{R}^{\mathbf{2}}$ & $\mathbf{F}$ & $\mathbf{P}$ \\
\hline Schadenfreude & 0.016 & 3.598 & 0.050 & 0.063 & 4.636 & 0.004 \\
\hline
\end{tabular}

As shown in table (2) the results indicate that the relationship between envy and interpersonal conflict is significantly positive at $\mathrm{p}=0.003$, leading to the acceptance of hypothesis one that envy is positively related to interpersonal conflict. Similarly, results show that envy is positively related to schedenfreude, with the significance value at $\mathrm{p}=0.05$, resulting in the acceptance of hypothesis two as well. Table (2) further indicates that the relationship between schandenfreude and interpersonal conflict is also significantly positive at $\mathrm{p}=0.01$, which leads to the acceptance of hypothesis three as well.

As per the regression mediation analysis, the relationship between envy and interpersonal conflict, through schandenfredue (path $c^{\prime}$ ) is significant at $\mathrm{p}=0.08$, leading to the acceptance of hypothesis four, i.e. schadenfreude mediates the relationship between envy and interpersonal conflict. But the direct relationship between envy and interpersonal conflict is slightly more significant at $\mathrm{p}=0.001$, which means that schadenfreude partially mediates the said relationship.

To test the moderating role of workplace ethics, moderated regression analysis was performed using Preacher and Hayes method (2008). Though, as per table (2) results, schadenfreude has a significant impact on interpersonal conflict, but after incorporating work ethics as the moderator, the significance of the relationship decreases from 0.004 to 0.050 ; along with the decrease in the value of $\mathrm{R}^{2}$ to 0.016 . Therefore, moderation results conclude that work ethics moderate the relationship between schadenfreude and interpersonal conflict, such that it weakens the said relationship, hence leading to acceptance of hypothesis five.

\section{DISCUSSION}

As per the regression analyses, all the hypotheses have been accepted. The findings of the study suggest that envy does lead to the interpersonal conflict among employees, and schadenfreude mediates this positive relationship between envy and interpersonal conflict. On the other hand, by incorporating work ethics as a moderator between schadenfruede and interpersonal conflict, this relationship is buffered, leading to the conclusion that work ethics is not only negatively associated with schadenfruede and interpersonal conflict, it also negatively moderates the relationship between the two.

Although, all the results are aligned with the previous literature, the findings could further be substantiated by incorporating the contextual element. The partial mediation of the schadenfreude is explained using Hofstede's (1984) study Cultural Dimensions in Management and Planning; according to which, Pakistan being the higher power distance society, negative feelings experienced by employees at workplace, i.e. Schadenfreude, seldom result in explicit and extrovert manifestation of its consequential negative emotions, such as interpersonal conflict. Although, feeling of envy at workplace is very much common and manifested in behaviors leading to conflict, Schandenfreude, is a strong and a negative emotion that, even if experienced, is rarely admitted and reported by the employees.

Moderated Regression Analysis results show that Work ethics moderate the relationship between Schadenfreude and Interpersonal conflict, i.e. work ethics weaken the direct relationship. As backed by literature, work ethics prevent employees at workplace from experiencing negative emotions toward their coworkers, such as envy and Schadenfreude, ultimately leading to the interpersonal conflict. In Pakistani context, being a society in which religion plays a major part in day to day life and has a greater influence on 
the individual's approach towards life, be it personal or professional setting, work ethics certainly play their role in simmering down the negative impact of the negative workplace behaviors and emotions.

\section{Implications}

The study could have sound implications for nurses in Pakistan. Nursing, as well as overall medical profession in Pakistan is pretty much under researched and overworked (Settle, 2010). This could help administration understand how to deal with negative work behaviors leading to the interpersonal conflicts. Nursing is a very demanding and exhausting job not only physically but emotionally; by the virtue of the fact that nurses have to deal with the patients much more than doctors, a lot of the times. Different workplace behaviors triggered by certain negative emotions not only affect the performance of the nurses but could have lasting and more serious affects on patients as well. This study is just an endeavor to provide foundation to understand how interpersonal conflicts among nurses can be reduced by incorporating work ethics and dealing with such negative emotions that can lead up to interpersonal conflicts.

\section{LIMITATIONS}

Although, the study is an attempt to get an insight into the reasons of interpersonal conflicts, it is not without certain limitations. One of the major limitations of the study is considering only one antecedent of interpersonal conflict, i.e. Envy. There are several other relevant variables that lead to Schadenfreude and Interpersonal conflict. Incorporating more variables would not only increase the model fitness but will provide the clearer picture. Apart from that the sample is taken from the Rawalpindi/ Islamabad region. In order to get more generalized results and get a bigger picture, data from across the country need to be collected.

\section{FUTURE DIRECTIONS}

This research can further be refined by incorporating more relevant variables in order to study the causes of interpersonal conflicts. Nature of relationship quality, such as Leader member exchange relationship can also help understand the antecedents of conflict. Although work ethics moderate the relationship, adding certain other variables such as personality type can give somewhat different and interesting insight into the phenomenon.

\section{REFERENCES}

Aldag, R., \& Brief, A. (1975).Some Correlates of Work
Values. Journal of Applied Psychology, 60(6), 757760.

Ashforth, B. E., \& Humphrey, R. H. (1995). Emotion in the workplace: A reappraisal. Human Relations, 48(2), 97-125.

Aycan, Z., Kanungo, R., Mendonca, M., Yu, K., Deller, J., Stahl, G., \&Kurshid, A. (2000). Impact of culture on human resource management practices: A 10country comparison. Applied Psychology, 49(1), 192-221.

Barki, H., \&Hartwick, J. (2001).Interpersonal conflict and its management in information system development. Mis Quarterly, 195-228.

Barki, H., \&Hartwick, J. (2004).CONCEPTUALIZING THE CONSTRUCT OF INTERPERSONAL CONFLICT. International Journal of Conflict Management, 15(3), 216.

Barnett, T., \&Vaicys, C. (2000).The moderating effect of individuals' perceptions of ethical work Climate on Ethical judgement and behavioral intentions. Journal of Business Ethics, 47(4), 351.

Bedeian, A. G. (1995).Workplace envy. Organizational Dynamics, 23(4), 49-56.

Berscheid, E., \& Reis, H. T. (1998).Attraction and close relationships. The handbook of social psychology, 2, 193-281.

Bobette, B. (1993). What are ethics? Journal of the American Society of CLU \& ChFC, 47(3), 28.

Cabrales, A. (2010). The causes and economic consequences of envy.SERIEs, 1(4), 371-386.

Chaudhuri, A. (1985). Formal properties of interpersonal envy. Theory and Decision, 18(3), 301-312.

Cikara, M., \& Fiske, S. T. (2013). Their pain, our pleasure: stereotype content and schadenfreude. Annals of the New York Academy of Sciences, 1299(1), 52-59.

Cowan-Jenssen, S. U. E. (2011). Envy: Everyday and Everywhere. Psychotherapy and Politics International, 9(1), 43-51.

Darwin, C. (1998). The expression of the emotions in man and animals.Oxford University Press.

DeWall, C. N., Gillath, O., Pressman, S. D., Black, L. L., Bartz, J. A., Moskovitz, J., \&Stetler, D. A. (2014). When the Love Hormone Leads to Violence Oxytocin Increases Intimate Partner Violence Inclinations Among High Trait Aggressive People. Social Psychological and Personality Science, 1948550613516876.

Dhami, M., \& Olsson, H. (2008).Evolution of the interpersonal conflict paradigm. Judgment and Decision Making, 3(7), 547-569.

Dogan, K., \&Vecchio, R. P. (2001).Managing envy and jealousy in the workplace. Compensation \& Benefits Review, 33(2), 57-64. 
Douglas, M. M. (2002). Administering the employment relationship: The ethics of conflict Resolution in Relation to justice in the workplace. Journal of Business Ethics, 1/2, 33.

Ekman, P. (2003). Emotions revealed: Recognizing faces and feelings to improve communication and emotional life. New York, NY: Times Books.

Feather, N. T., \&Nairn, K. (2005). Resentment, envy, schadenfreude, and sympathy: Effects of own and other's deserved or undeserved status. Australian Journal of Psychology, 57(2), 87-102.

Feather, N. T., \& Sherman, R. (2002). Envy, resentment, schadenfreude, and sympathy: Reactions to deserved and undeserved achievement and subsequent failure. Personality and Social Psychology Bulletin, 28(7), 953-961

Ford, F., \&Herren, R. V. (1993). The Teaching of Work Ethics: Current Practices of Work Program Coordinators in Georgia. Paper presented at the American Vocational Association Convention, 143.

Fredrickson, B. L. (2003). Positive emotions and upward spirals in organizations. Positive Organizational Scholarship, 163-175.

Gelfand, M. J., Erez, M., \&Aycan, Z. (2007).Crosscultural organizational behavior. Annu. Rev. Psychol., 58, 479-514.

Greenhalgh, L., Neslin, S. A., \&Gilkey, R. W. (1985). The effects of negotiator preferences, situational power, and negotiator personality on outcomes of business negotiations. Academy of Management Journal, 28(1), 9-33.

Hareli, S., \& Weiner, B. (2002). Dislike and envy as antecedents of pleasure at another's misfortune. Motivation and Emotion, 26(4), 257-277.

Heider, F. (1958).The psychology of interpersonal relations. NY: J. Wiley \& Sons.

Henri, B., \& Jon, H. (2001).Interpersonal conflict and its management in information system development. MIS Quarterly, 25(2), 194.

Hill, S. E., \& Buss, D. M. (2006).Envy and positional bias in the evolutionary psychology of management. Managerial and Decision Economics, 27(2-3), 131-143.

Hofstede, G. (1984). Cultural dimensions in management and planning. Asia Pacific Journal of Management, 1(2), 81-99.

James, S., Kavanagh, P. S., Jonason, P. K., Chonody, J. M., \&Scrutton, H. E. (2014). The Dark Triad, schadenfreude, and sensational interests: Dark personalities, dark emotions, and dark behaviors. Personality and Individual Differences, 68, 211216.

Jehn, K. (1997). A qualitative analysis of conflict types and dimensions in organizational groups. Administrative Science Quarterly, 42, 530-57.

Kim, S., O’Neill, J. W., \& Cho, H. M. (2010). When does an employee not help coworkers? The effect of leader-member exchange on employee envy and organizational citizenship behavior. International Journal of Hospitality Management, 29(3), 530537.

Leach, C. W., Spears, R., Branscombe, N. R., \&Doosje, B. (2003). Malicious pleasure: schadenfreude at the suffering of another group. Journal of Personality and Social Psychology, 84(5), 932.

Lee, B. (1994). Putting ethics to work in public relations. Executive Speeches, 9(1), 62.

Li, M. (2012).Rationalizing the Pleasure in Another Group's Suffering: From Schadenfreude to Dehumanization.

Martínez-Corts, I., Boz, M., Medina, F., Benítez, ,., \&Munduate, L. (2011). Coping with Interpersonal Conflict at Work in Small Business:The Moderating Role of Supervisor and Co-Worker Support. Revista de PsicologíadelTrabajo y de lasOrganizaciones, 27, 117-129.

Miller, M. J., Woehr, D. J., \& Hudspeth, N. (2002). The meaning and measurement of work ethic: Construction and initial validation of a multidimensional inventory. Journal of Vocational Behavior, 60(3), 451-489.

Muchinsky, P. M. (2000). Emotions in the workplace: The neglect of organizational behavior. Journal of Organizational Behavior, 21(7), 801-805.

Nickerson, J. A., \& Zenger, T. R. (2008).Envy, comparison costs, and the economic theory of the firm. Strategic Management Journal, 29(13), 14291449

Nietzsche, F. (1967). On the genealogy of morals (Translated by W. Kaufmann \& R.J. Hollingdale, originally published 1887). New York: Random House.

Panksepp, J. (1998). Affective neuroscience: The foundations of human and animal emotions. Oxford university press.

Parrott, W. G., \& Smith, R. H. (1993).Distinguishing the experiences of envy and jealousy. Journal of Personality and Social Psychology, 64(6), 906.

Powell, C. A., \& Smith, R. H. (2013). Schadenfreude Caused by the Exposure of Hypocrisy in Others. Self and Identity, 12(4), 413-431.

Prone, M. (2000). Interpersonal Conflict at Work and Psychological Outcomes:Testing a Model Among Young Workers. Journal of Occupational Health Psychology, 5(2), 246-255.

Rafaeli, A., \& Sutton, R. I. (1989).The expression of emotion in organizational life. Research in 
Organizational Behavior, 11(1), 1-42.

Rawls, J.: 1971, A Theory of Justice, Harvard University Press, Cambridge (Mass.).

Scott, W. (2007).The Inevitability of Conflict. Security ABI/INFORM Global, 44(8), 32.

Settle, A. (2010). Federal Budget: Health Sector. Post Budget Orientation Series for Honorable Parliamentarians.

Simmel, G. (2010). Conflict and the web of group affiliations.Simon and Schuster.

Smith, R. H., Parrott, W. G., Ozer, D., \& Moniz, A. (1994). Subjective injustice and inferiority as predictors of hostile and depressive feelings in envy. Personality and Social Psychology Bulletin, 20(6), 705-711.

Smith, R.H., Turner, T.J., Garonzik, R., Leach, C.W., Urch, V., \& Weston, C. (1996).Envy and schadenfreude. Personality and Social Psychology Bulletin, 22, 158-168.

Spector, P. E., \&Jex, S. M. (1998). Development of four self-report measures of job stressors and strain: Interpersonal Conflict at Work Scale, Organizational Constraints Scale, Quantitative Workload Inventory, and Physical Symptoms Inventory. Journal of Occupational Health Psychology, 3(4), 356.

Staw, B. M., Sutton, R. I., \&Pelled, L. H. (1994). Employee positive emotion and favorable outcomes at the workplace. Organization Science, 5(1), 5171.
Takahashi, H., Kato, M., Matsuura, M., Mobbs, D., Suhara, T., \& Okubo, Y. (2009). When your gain is my pain and your pain is my gain: neural correlates of envy and schadenfreude. Science, 323(5916), 937-939.

Van Dijk, W. W., Ouwerkerk, J. W., Goslinga, S., \&Nieweg, M. (2005).Deservingness and Schadenfreude. Cognition and Emotion.

Van Dijk, W. W., Ouwerkerk, J. W., Goslinga, S., Nieweg, M., \&Gallucci, M. (2006). When people fall from grace: Reconsidering the role of envy in schadenfreude. Emotion, 6(1), 156.

Vecchio, R. (2005). Explorations in employee envy: Feeling envious and feeling envied. Cognition \& Emotion, 19(1), 69-81

Veroff, J., Douvan, E., \&Kulka, R. A. (1981). The inner American: A self-portrait from 1957 to 1976 . New York: Basic Books.

Virovere, A., Kooskora, M., \& Valler, M. (2002).Conflict as a tool for measuring ethics at workplace. Journal of Business Ethics, 39(1/2), 75.

Weisel-Barth, J. (2008). Analyst envy in working with an artist: Four scenes. Psychoanalytic Dialogues, 18(6), 735-757.

Wharton, A. S., \& Erickson, R. I. (1993). Managing emotions on the job and at home: Understanding the consequences of multiple emotional roles. Academy of Management Review, 18(3), 457486. 